Hylotoma scapularis Klug. - The fullgrown larvae have a pretty general resemblance to those of $H$. pectoralis Leach $(=H$. dulciaria Say),* and are about $18 \mathrm{~mm}$. long. Head light orange yellow, body somewhat flattish and light yellowish green in color. There are six distinct rows of small closely adjoining black spots on the upper portion of the body extending from the head to the anal segment. On each of the fleshy projections on the sides of the segments, except the last, there is an oblong dark spot; but these spots above the two posterior pair of true legs appear as two large somewhat triangular black blotches. Above the anal segment there is a large oval shaped black spot. The legs are black on the outer side, and the prolegs are marked by a dark brown blotch on the outer side. The black legs and black blotch on the anal segment are the chief marks which distinguish this larva from that of $H$. pectoralis in which the legs and anal segment are yellowish. The cocoons are of a dirty white or light brown color and average about $12 \mathrm{~mm}$. in length. They are composed of two walls, the inner being closely, and the outer loosely spun.

The eggs are deposited along the margins of the leaves of the common American elm (Ulmus Americana) upon which the larvae feed. Young larvae were found early in Au- gust and those observed attained full growth about the end of the month. Two males and many females were raised from these about the first of July following.

Hylotoma McLeayi Leach. Full grown larva from ${ }_{5}$ to $18 \mathrm{~mm}$. long. Head black. Body flattish; pale yellowish green, with four distinct lines of black spots along the back extending from the head to the anal segment; and with some minute, less regularly arranged spots or dots along the sides above the fleshy projections which characterize larvae of this genus. Each fleshy projection bears a long narrow black spot. The anal segment is surmounted by a large irregular oval black blotch and is brown above the anus. The legs are dark brown or black on the outer base and have a heavy black blotch at the base. The prolegs are marked on their outer side by a somewhat triangular, black or very dark brown spot. The cocoon is double walled, the outer wall being loosely woven and it is dull white or pale brown in color, and is from $12-14 \mathrm{~mm}$. in length.

The larvae were found in considerable numbers in the month of August feeding upon the foliage of common choke-cherry (Prunus Virginiana) at Jamaica Plain, Mass. From these larvae a number of female imagos were bred in the latter part of the month of May following.

\title{
A NOVEL DIAGRAMMATIC REPRESENTATION OF THE ORDERS OF INSECTS.†
}

The difficulty of representing satisfactorily by any linear arrangement the relations of the orders to each other and to Thysanura has compelled us to give diagrams I-III. Diagram II [pl.

\footnotetext{
* See T. W. Fyles in Canadian entomologist, v. 18 , p. 38 ; v. 19, p. 59 .
}

I] shows by parallel bars rising above the circular plate, which represents the surface of the earth, the sixteen orders of insects as they exist to-day, and below this plate the different orders are ar-

$\dagger$ Reprinted from Guides for Science Teaching. No. VIII. Insecta. By Alpheus Hyatt and J. M. Arms. 
ranged in converging bars according to their supposed relations during geologic times. This last is purely theoretical, since the present state of our knowledge of fossil insects is too fragmentary and unsatisfactory to afford sufficient evidences for the demonstration of such a classification.

Diagram II [pl. I] represents the opposite or farther side of Diagram I, the plate having been turned around so that the orders X-XVI can be more clearly seen both above and below the earth's surface. Diagram III is a view from above the circular plate giving in

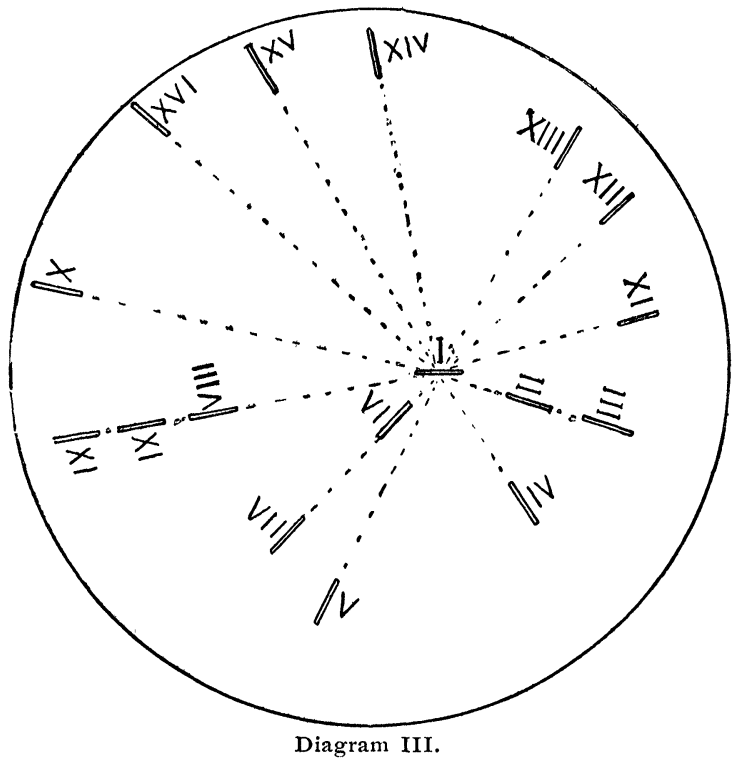

horizontal section the position of the orders. In Diagrams I, II, $A$ represents the wingless, primitive, or Thysanuran stock. The stems $B, B^{\prime \prime}$, $B^{\prime \prime \prime} *$, Diagram I; $B^{\prime}, B^{\mathrm{IV}}$, Diagram II, represent the winged stocks which sprang from $A$. These may have been composed, so far as the facts now known are concerned, of a number of separate or branching lines leading up to the various orders as termini of more or less distinct stocks. $\dagger$

The line $B^{\prime}$ in Diagram II indicates the winged stock from which the true Neuroptera sprang, and so far as we know, this may have been the same common stock as that from which the Ephemeroptera and Odonata also arose (Diagram I, $B)$. In spite of the introduction of the quiescent pupal stage in the Neuroptera, their obvious resemblances to the Odonata, and the fact that they still retain the Thysanuroid form of larva should not be overlocked: Diagram I recognizes these similarities, and presents the least modified and most ancient branches of the genealogical tree of the Insecta as near together as practicable. The placing of Thysanura near the centre, by means of a short

${ }^{*} B^{\prime} \prime \prime$ extends in the diagram to the orders Hemiptera and Thysanoptera instead of to the stem from which these orders sprang. It is placed here because the stem proper is out of sight, being farther down and behind $B$ and $B \prime \prime$.

$\dagger$ For example, as suggested by Packard in Third Rep. U. S. Ent. Com., p. 289, the Dermaptera may have been derived from a form similar to Japyx, a curious Thysanuran genus, and since it has characters allying it both to Orthoptera and Coleoptera, it may be the existing descendant of some common forms from which both of these orders originated. The Thysanura stand, according to Comstock, in a similar position with relation to the Hem. iptera. 
Psyche, I8gr, vol. 6.

Plate I.

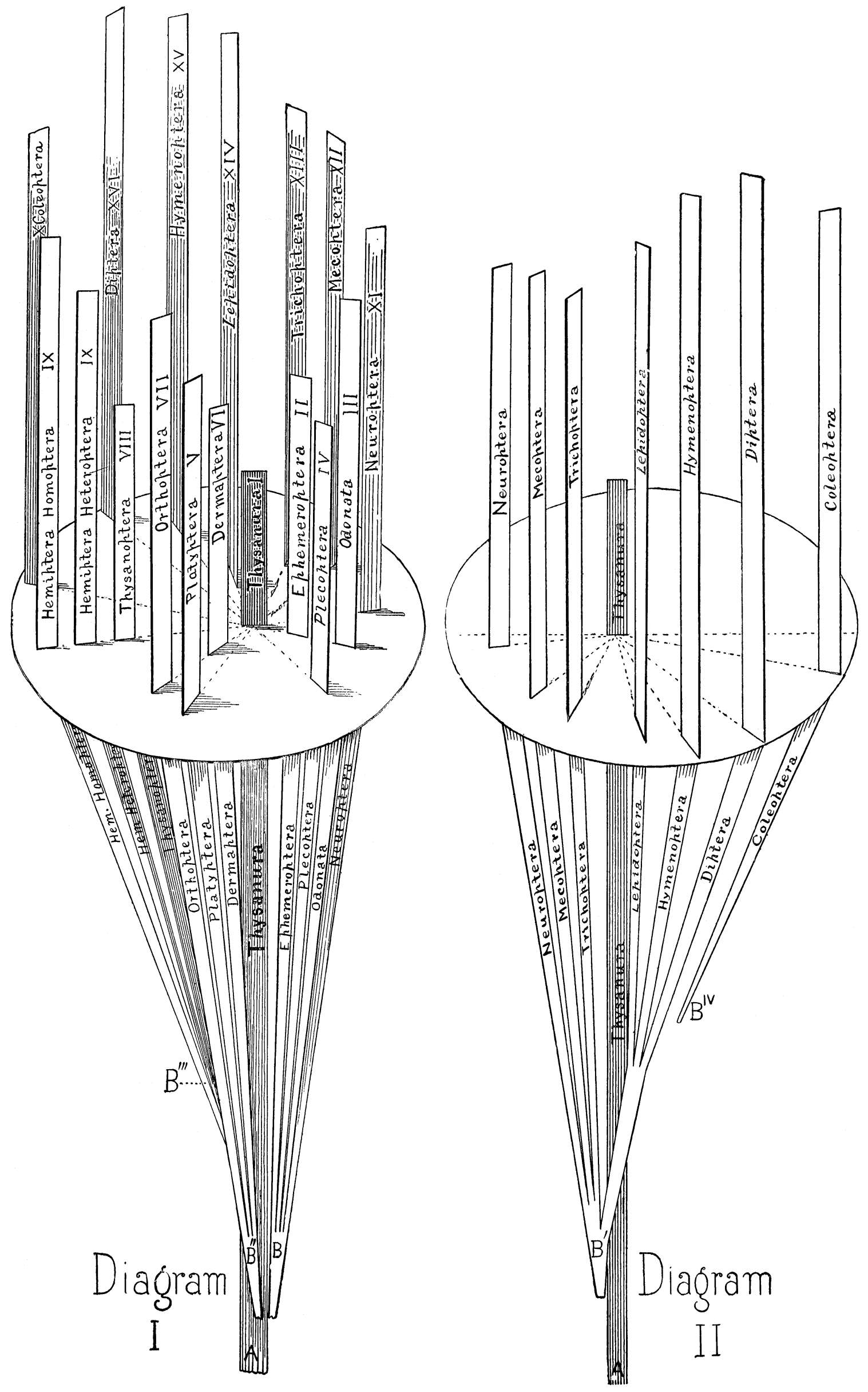


vertical line, $*$ indicates the essentially generalized and larval character of the order, and does not necessarily imply any nearer relationship to Neuroptera, which stands on the right, than to Coleoptera on the extreme left. The height to which the vertical bars have been carried above the plate is a rough approximation to the specialization attained by the adults, and also to the removal of the mode of development from the primitive Thysanuroid mode.

The orders existing to-day are regarded as parallel series differing from each other in structure, and not as yet connected by well-known intermediate forms. Where the probability exists that certain orders have had a common origin, they are placed on the same radiating lines, as seen in Diagram III, orders II-III ; also VI-VII, and VIIIIX; and this rule has been departed from only where the data seemed to justify a more natural interpretation, as

in the case of the orders from XII to XVI, inclusive.

All of these graphic presentations are necessarily extremely rough approx imations to the actual facts, and present even the authors' views in a very im. perfect manner. Nevertheless, if conscientiously studied, they will, it is hoped, help to give teachers some ideas of the principles upon which a classification is based, and prevent them from falling into the absurd but natural mistakes often occasioned by the linear treatment of types in the text.

\section{LIST OF ORDERS.}

I. Thysanura.

II. Ephemeroptera.

III. Odonata.

IV. Plecoptera.

V. Platyptera.

VI. Dermaptera.

VII. Orthoptera.

VIII. Thysanoptera. XVI. Diptera.
IX. Hemiptera.

X. Coleoptera.

XI. Neuroptera.

XII. Mecoptera.

XIII. Trichoptera.

XIV. Lepidoptera.

XV. Hymenoptera.

\section{DESCRIPTIONS OF THE LARVA AND PUPA OF SCOTOBATES CALCARATUS FABR.}

BY WM. BEUTENMULLER, NEW YORK.

LARVA :-Head subquadrate, anterior angles obtusely rounded, sides moderately rounded. shining. Clypeus tranverse, about three times as broad as long, oblique. Labrum smaller than the clypeus, anterior margin rounded and beset with a few bristle-like hairs. Antennae three jointed, first joint cylindrical, about twice as long as broad;

* See also the diagram given by Packard in Third Rep. U.S. Ent. Com., 1883, p. 295. second joint considerably longer, clavate; third joint minute, cylindrical, with a few hairs at the apex. Mandibles short, stout, arcuate externally, excavate internally, apex tridentate, base with a prominent elevation with two small teeth. Maxillae subcylindrical, stout, elongate, lobe somewhat truncate at the apex with a number of bristle-like hairs. Maxillary palpi three jointed, first joint stout, cylindrical, broader than long; 

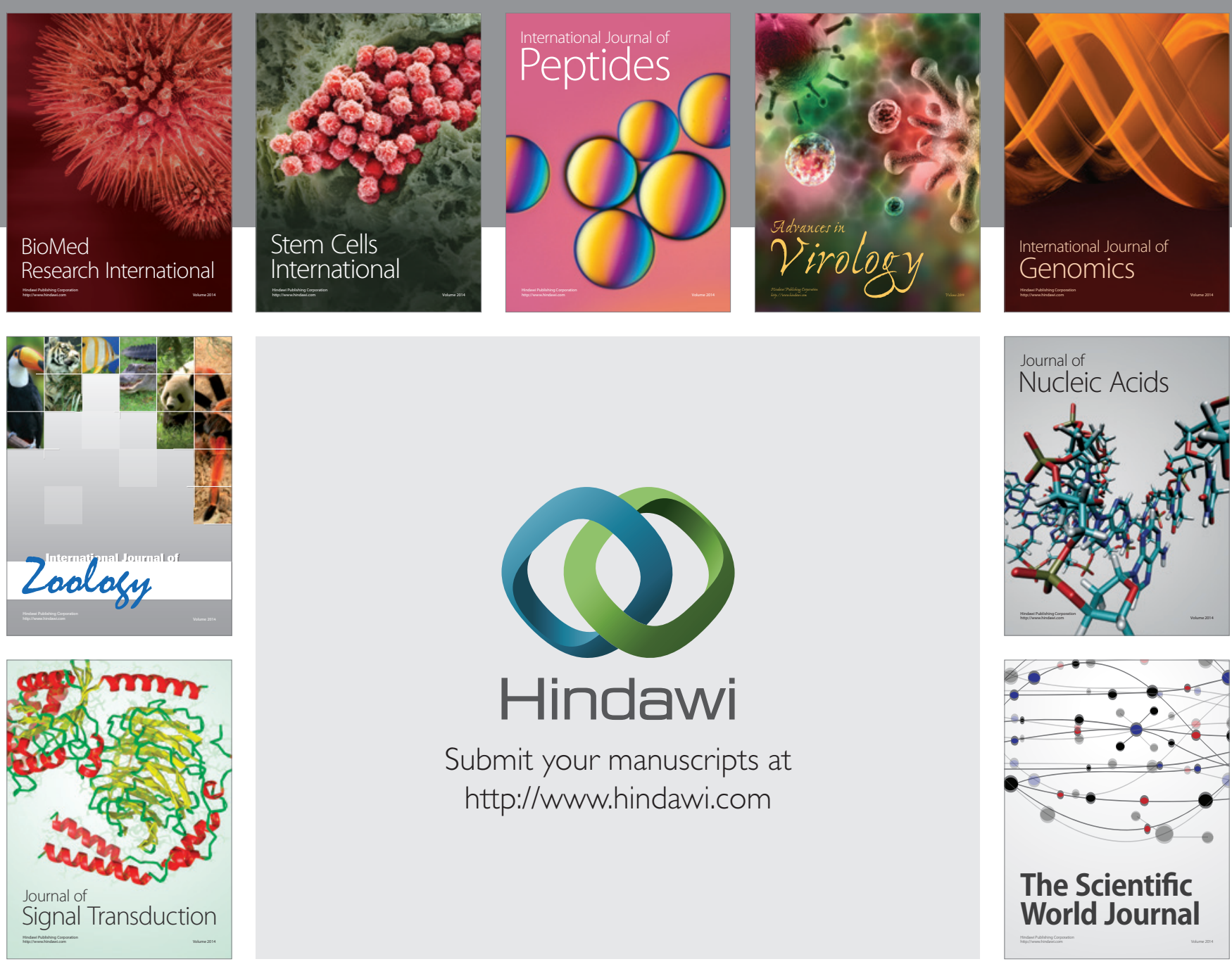

Submit your manuscripts at

http://www.hindawi.com
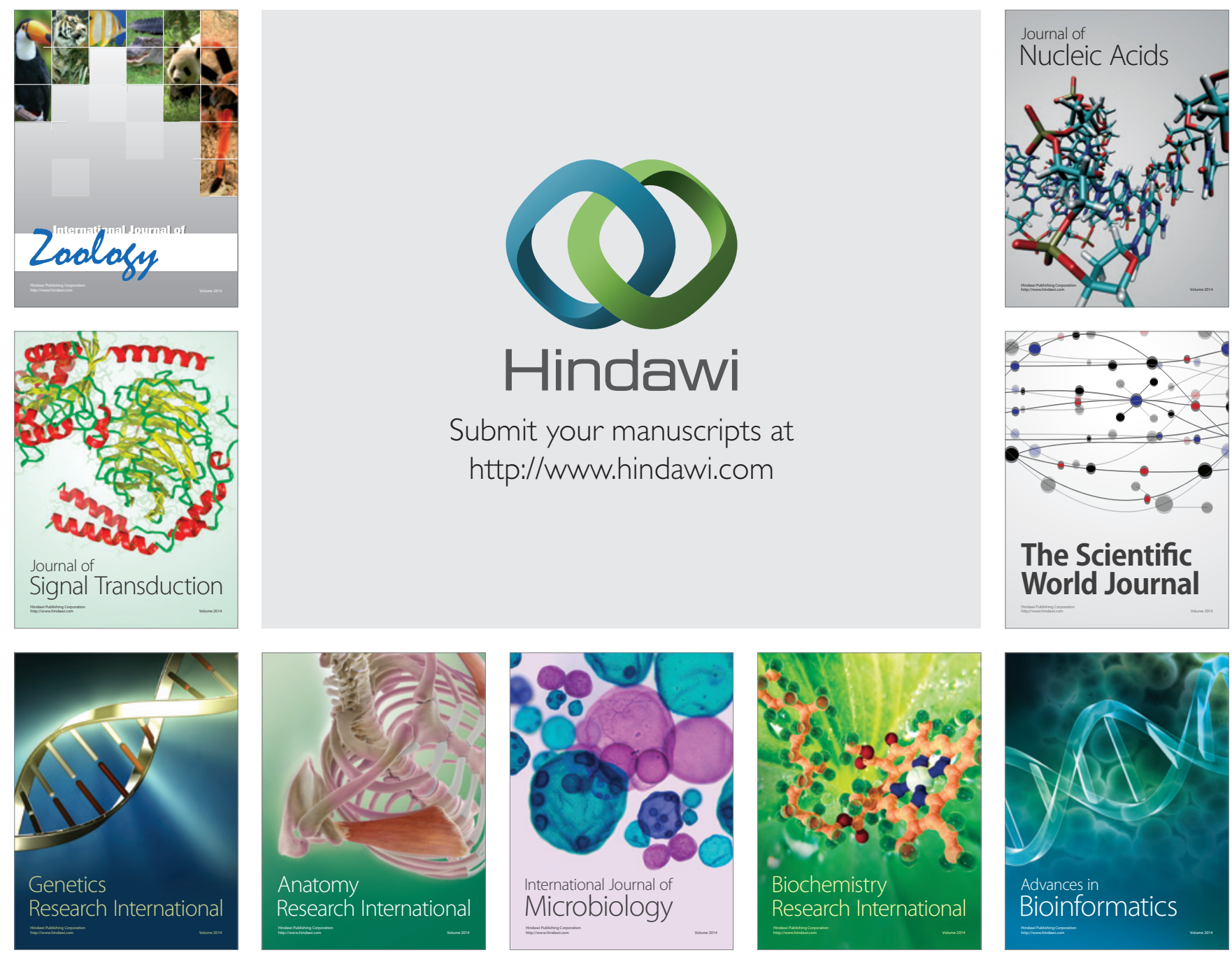

The Scientific World Journal
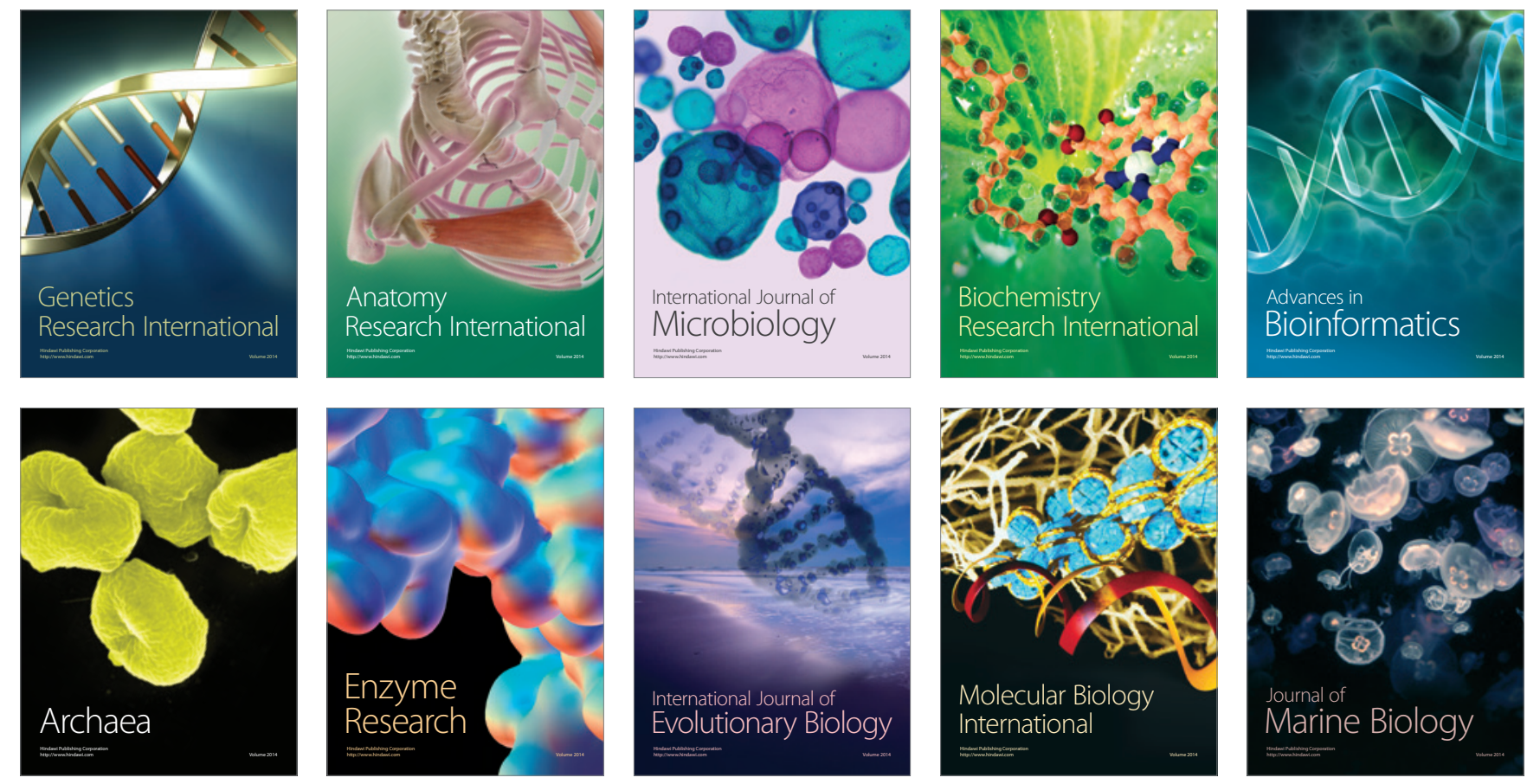